\title{
Piriform Aperture Morphometry and Nasal Bones Morphology in Brazilian Population by Postero-Anterior Caldwell Radiographys
}

\author{
Morfometría de la Apertura Piriforme y Morfología de los Huesos Nasales \\ en la Población Brasileña por la Radiografía Postero-Anterior de Caldwell
}

"Felippe Bevilacqua Prado; ** Ricardo Armini Caldas; *Ana Cláudia Rossi; *Alexandre Rodrigues Freire; **** Francisco Carlos Groppo; *Paulo Henrique Ferreira Caria \& ${ }^{* *}$ Eduardo Daruge Júnior

\begin{abstract}
PRADO, F. B.; CALDAS, R. A.; ROSSI, A. C.; FREIRE, A. R.; GROPPO, F. C.; CARIA, P. H. F. \& JÚNIOR, E. D. Piriform aperture morfometry and nasal bones morphology in Brazilian population by postero-anterior Caldwell radiographys. Int. J. Morphol., 29(2):393-398, 2011.
\end{abstract}

SUMMARY: Piriform aperture and nasal bone contribute to the formation of the nose. Its morphology varies according to ethnic group and gender. The piriform apertures and nasal bones of 97 individuals were examined radiographically through Caldwell radiographic technique and the types of nasal bones were classified according to Hwang et al. (2005). The width, height and area of piriform aperture were measured to demonstrate the difference according to gender. Statistical analysis was performed from the Student $t$ test and analysis of variance (ANOVA). The most frequent type of nasal bone was A, and D was the most uncommon in both genders. In the Student $t$ test significant differences between genders, height, width and area of the piriform aperture were obtained and were larger in males when compared to females. The dimensions of the piriform aperture were higher in males when compared to females, and therefore may be used as parameter for the distinction of gender in Brazilian population. The type A of nasal bone was the most frequent in the Brazilian population, contributing to ethnic differentiation in human identification.

KEY WORDS: Nasal bones; Morphometry; Nasal cavity; Skull.

\section{INTRODUCTION}

Several parameters can be applied in case of facial reconstruction from the skull of an unknown individual (Anderson et al., 2008). The width and position of the mouth and the projection of the eyeball are used to determine the facial features (Swan \& Stephan, 2005; Stephan, 2003; Taylor, 2001; Wilkinson, 2004). These parameters are incomplete in the nasal area and insufficient for the recognition of an individual (Anderson et al.).

The piriform aperture and nasal bones morphology vary according to ethnic groups (Lee et al., 2008). This morphological variability is necessary to understand the ethnic differences (Lee et al.), and can be analyzed by radiography in forensic context (Sforza et al., 2004; Vitte $e t$ al., 1982).

The morphological variations of the piriform aperture and nasal bone can be used in Forensic Medicine and Forensic Dentistry, because its knowledge may be applied to the sexual and ethnic differentiation (Hwang et al., 2005). Rogers (2005) and Williams \& Rogers (2006) stated that the shape of the piriform aperture is an important indicator for sex identification.

In addition to forensic implications, the knowledge of the piriform aperture and nasal bones variations is fundamentally significant in Anthropology and Otolaryngology (Hwang et al.). In Medicine there are few studies on the extent of the piriform aperture and nasal bone (Abdelkader et al., 2005). Alterations in the shape of these structures are frequent and should be considered in planning a rhinoplasty. Hommerich \& Riegel (2002) noted that the shape and width of piriform aperture exert significant impact on the effectiveness of nasal breathing.

\footnotetext{
* Department of Morphology, Piracicaba Dental School, State University of Campinas, Brazil.

** Department of Social Odontology, Piracicaba Dental School, State University of Campinas, Brazil.

**** Department of Physiological Sciences, Piracicaba Dental School, State University of Campinas, Brazil.
} 
Several radiographic techniques are used to determine the values of the dimensions of craniofacial anatomical structures. The posteroanterior Caldwell radiographic technique is effective to identify the gender of Brazilian ethnic group (Camargo et al., 2007).

Considering the high heterogeneity of the Brazilian population, the aim of this study was to evaluate the morphology of the piriform aperture and nasal bone in Brazilian subjects and contributes with the forensic anthropology.

\section{MATERIAL AND METHOD}

Radiographs of 97 individuals, taken by the Caldwell radiographic technique with front-nasal support (Fig. 1), were evaluated. The sample comprised 50 females and 47 males, between 18 and 36 years old, who were previously examined and evaluated with respect to anatomical and physiological integrity of the piriform aperture area. This study was approved by the Committee of Ethics in Research.

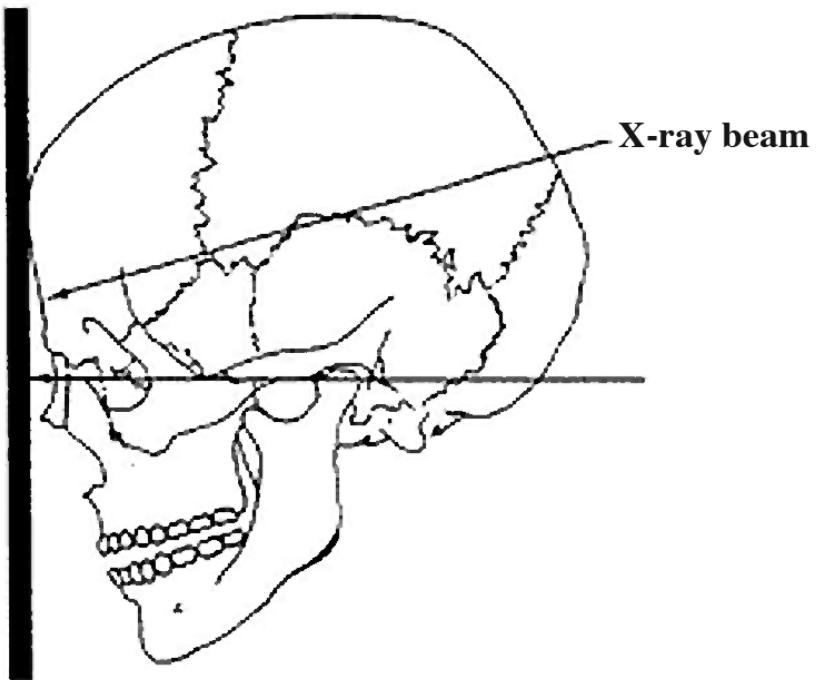

\section{Chassis film holders}

Fig. 1. Diagram of Caldwell radiographic technique with frontnasal support.

The radiographs were taken by the same radiologist, utilizing Kodak radiographic film, size 18 x 24 centimeters (cm). The posteroanterior teleradiography was performed with a X-Ray Telefunk X-15 apparatus with a distance of $1.52 \mathrm{~m}$ from source to film, using an exposure of $80 \mathrm{Kvp}$ and time of 1.2 seconds at $20 \mathrm{~mA}$.
Among the several techniques available to piriform apertures radiograph, the Caldwell radiographic technique with front-nasal support was selected, in which the proximity of the piriform apertures to the film produces less expansion and less distortion, resulting in an image closer to the real size (Camargo et al.). Diagram of Caldwell radiographic technique for examination of the piriform aperture is shown in Fig. 1. The contour of the piriform apertures were performed three times for each radiography, under the light of a light box using tracing paper and mechanical pencil with 0.5 millimeters $(\mathrm{mm})$ thick by the same examiner.

The bordering points of the radiographic images of the piriform aperture were obtained with the help of a transparency plate for an HP scanner connected to a PENTIUM II computer. The linear measurements and the areas of the piriform aperture were obtained using the program SIARCS 3.0 for Windows, developed by EMBRAPA - São Carlos - São Paulo - Brazil.

The highest width of the piriform aperture, the height of the piriform aperture were measured. The distance between the craniometrical points nasion and nasion-spinal area of the piriform aperture were also measured (Fig. 2).

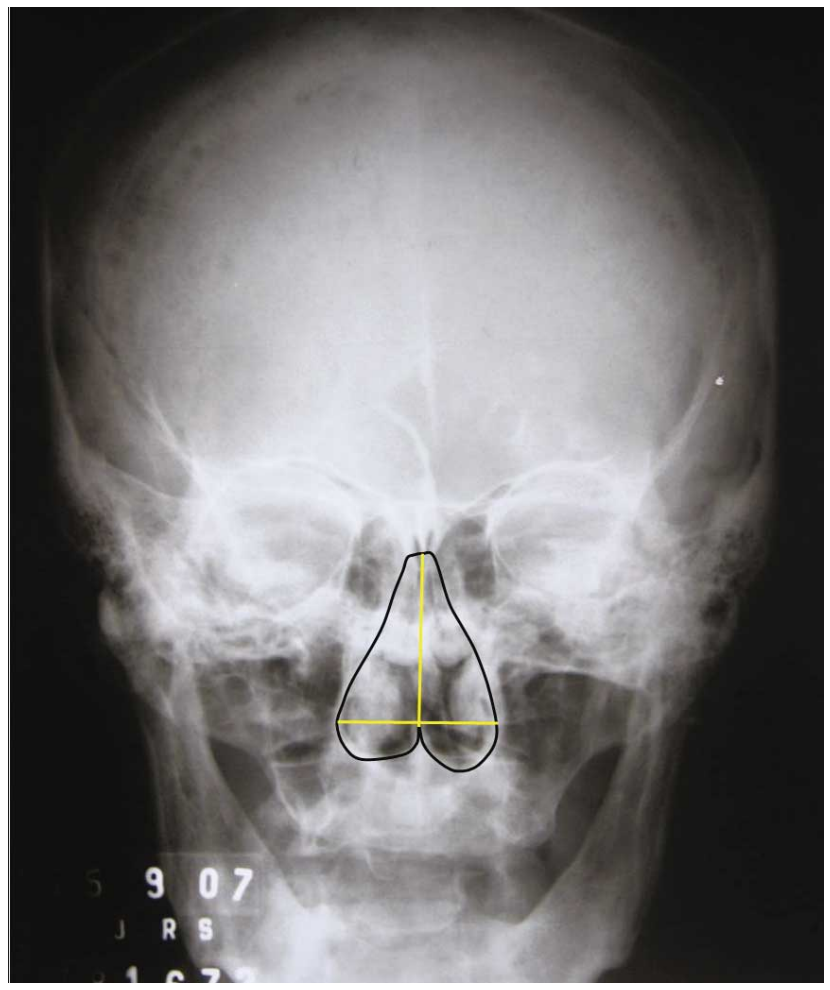

Fig. 2. Measures of piriform aperture: black contour represents the piriform aperture area; horizontal line (yellow) represents the width of the piriform aperture; and vertical line (yellow) represents the height of the piriform aperture. 
The linear measurements obtained from each radiograph were expressed in linear $\mathrm{cm}$ and the areas in square centimeters $\left(\mathrm{cm}^{2}\right)$.

The analysis was performed using analysis of variance (ANOVA) and Student $t$ test with significance level of $5 \%$ to verify the relation of the sex.
In addition to the morphometric analysis, the most common nasal bone shapes were classified, in order to determine the predominant features in Brazilian population and compare them with other populations, and to identify the prevalence in relation to sex. The nasal bone shapes were categorized according to the method of Hwang et al. (Fig. $3)$.
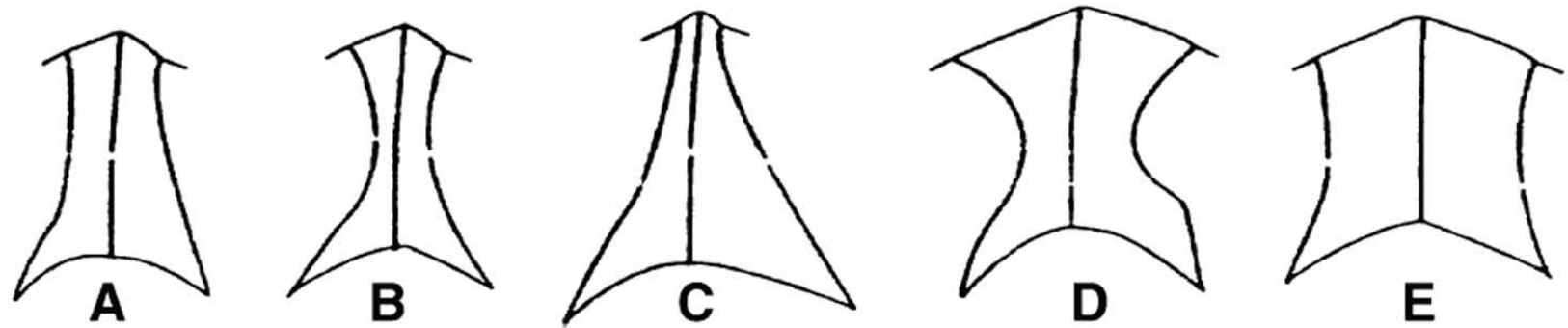

Fig. 3. Classification of nasal bones in five types according to Hwang et al. (2005).

\section{RESULTS}

Our results demonstrated that the most frequent type of nasal bone in the Brazilian population was the type A in both sexes (Table I). And the type D was the uncommon in both sexes (Table I).

Table I. Shows the quantity of nasal bones according to Hwang's classification and the gender of the subjects.

\begin{tabular}{lccccc}
\hline \multicolumn{6}{c}{ Nasal bone (Hwang`s classification) } \\
\hline Sex & A & B & C & D & E \\
\hline \multirow{2}{*}{ Female } & 28 & 11 & 7 & 1 & 3 \\
& $(28.9 \%)$ & $(11.3 \%)$ & $(7.2 \%)$ & $(1 \%)$ & $(3.1 \%)$ \\
\multirow{2}{*}{ Male } & 20 & 16 & 6 & 1 & 4 \\
& $(20.6 \%)$ & $(16.5 \%)$ & $(6.2 \%)$ & $(1 \%)$ & $(4.1 \%)$ \\
\hline
\end{tabular}

Data analysis (ANOVA) showed that no statistically significant differences among Hwang's classification levels according to height $(\mathrm{p}=0.9559)$ (Fig. 4$)$, width $(\mathrm{p}=0.2644)$ (Fig. 5) and area ( $\mathrm{p}=0.2059)$ (Fig. 6), were found.

The student $\mathrm{t}$ test showed highly statistically significant differences between sexes, the male measurements were higher than female considering height $(\mathrm{p}<0.0001)$, width $(\mathrm{p}=0.0026)$ and area $(\mathrm{p}<0.0001)$ of piriform aperture (Fig. 7).

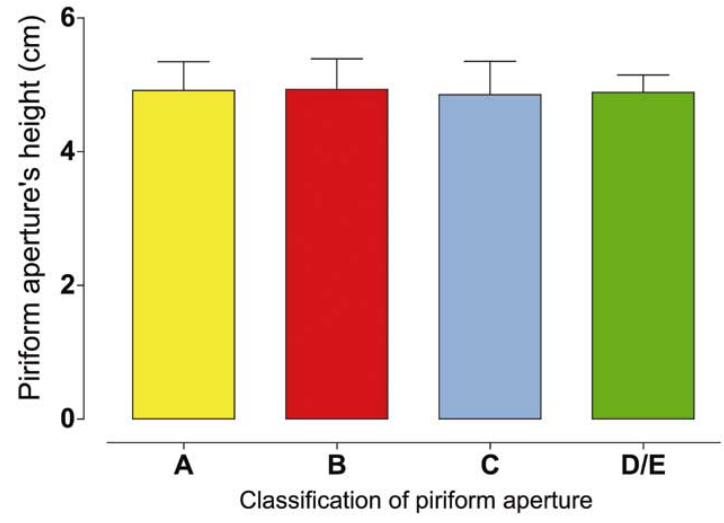

Fig. 4. Height of piriform aperture.

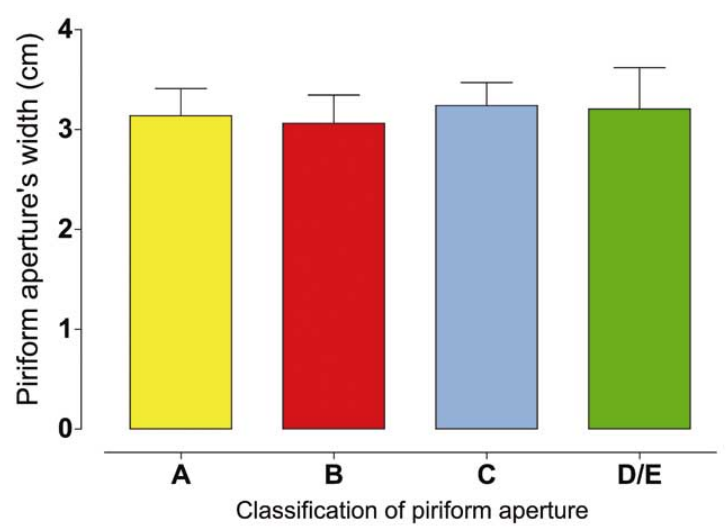

Fig. 5. Width of piriform aperture. 


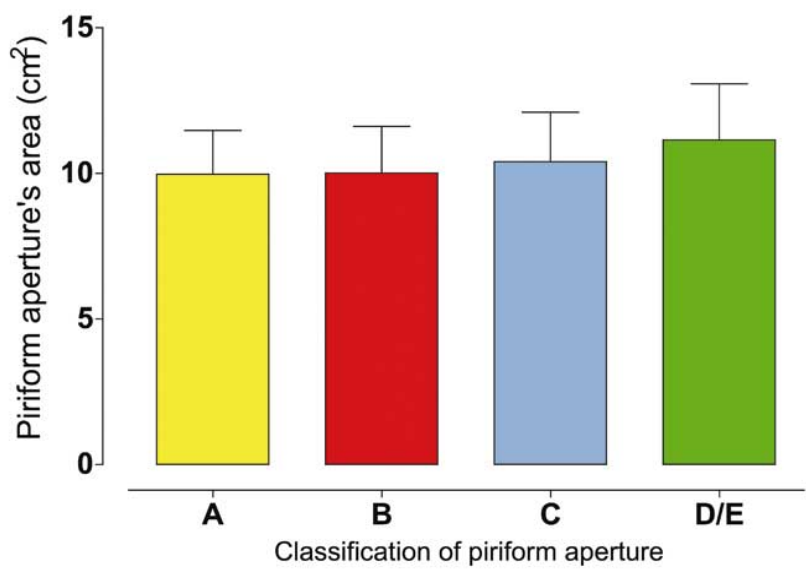

Fig. 6. Area of piriform aperture.

\section{DISCUSSION}

Anthropometry is used to obtain measurements of anatomical structures in order to assist in identifying the age, stature, sex and several aspects related to individual or ethnic group (Shrestha et al., 2009). In the human identification, especially in sex determination of isolated bones or complete skeleton, the process of analysis becomes increasingly complex (Prado et al., 2009).

The characteristics of the piriform aperture have been reported as a classic indicator of sexual differentiation (Cantín et al., 2009). Rogers and Williams \& Rogers affirmed that the area of the piriform aperture is an important indicator for sex identification.

The present study demonstrated by Caldwell radiographic technique, that the sex difference was highly significant and that height, width and area of the piriform aperture were higher in males than females in Brazilian subjects. Cantín et al., evaluated the width and height of the piriform aperture in 90 dry human skulls in the Brazilian population and concluded that these dimensions were significantly higher in male than female. The authors presented a mean height of $50 \mathrm{~mm}$ and width of $17.60 \mathrm{~mm}$ in male skulls, where as in females were $47 \mathrm{~mm}$ in length and $17.20 \mathrm{~mm}$ of width. The results of these authors and our work suggest that using different methods, it was established that the Brazilian male subjects have the dimensions of the piriform aperture larger than females. Demonstrating that specifying the values of bony anatomical structures of different populations is very important for sex determination in cases of partial or complete skeleton (Suazo et al., 2008).

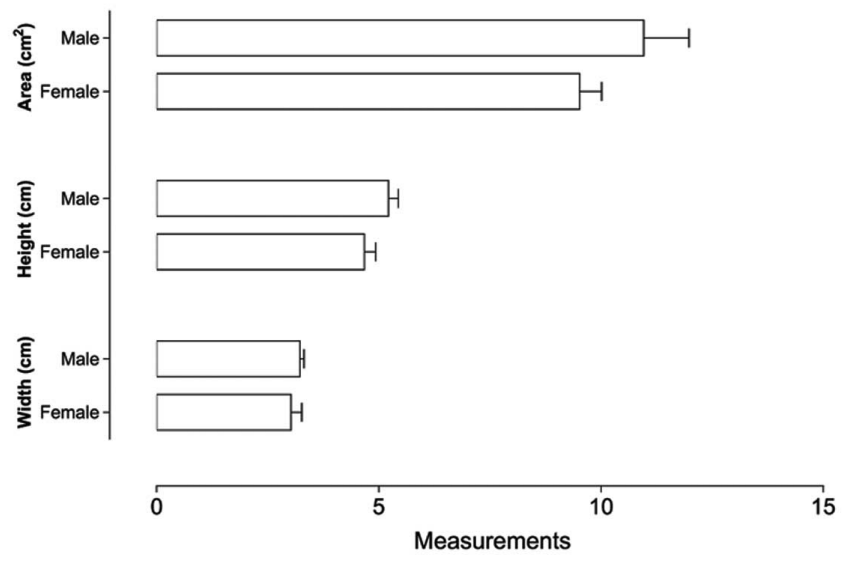

Fig. 7. Influence of sex in the piriform aperture measurements

Lang \& Baumeister (1982) classified the shape of the nasal bone of Germans into eight types. However, Hwang et al. simplified this complex classification method (Fig. 3). Hwang et al. reported that type B was more frequent in the Korean population and types D / E were not observed in Korean individuals. In this study, type A of nasal bone was the most common in Brazilian population and types D / E were the least frequent (Table I). Hwang \& Kang (2003) suggested that the dimensions of the piriform aperture and type of nasal bone are directly affected by the heat and humidity of the air breathed by the people. For this reason, it is believed that the dimensions of the piriform aperture and the shape of the nasal bone are adapted to the environment and geographical variations (Hwang \& Kang).

In other populations, as demonstrated by Hommerich \& Riegel in Germans skulls, showed the width of the piriform aperture smaller than that of our work. Hommerich \& Riegel (2002) had mean widths of $26 \mathrm{~mm}$ for male and $25 \mathrm{~mm}$ for female, whereas the present study had mean width of 35 $\mathrm{mm}$ and $30 \mathrm{~mm}$ respectively. Hwang et al. reported that height of the piriform aperture in Korean male individuals was $30.1 \mathrm{~mm}$ and females $28 \mathrm{~mm}$, and width of piriform aperture of these individuals was $25.7 \mathrm{~mm}$ and $25.4 \mathrm{~mm}$ for males and females, respectively. These data were lower than those obtained in Brazilian population in the present study; a mean height of $50 \mathrm{~mm}$ and $45 \mathrm{~mm}$ and width of $35 \mathrm{~mm}$ and $30 \mathrm{~mm}$ for Brazilian individuals of male and female individuals, respectively it was observed in this study. Anthropological studies have suggested that climatic influences may affect the width and the height of the piriform 
aperture (Wolpoff, 1968). For this reason, it is believed that the dimensions of the piriform aperture are adapted to the environment and geographical variations (Hwang \& Kang).

Erdem et al. (2004) analyzed 80 Turkish adult skulls and found that the value of piriform aperture width was 21.9 $\mathrm{mm}$ for males and $21 \mathrm{~mm}$ for females, lower values than those observed in Brazilian population in this study. Lee et al. after measure in three-dimensional computed tomography the width of piriform aperture of 75 Koreans, demonstrated that dimension was significantly higher in men than women, similar to the results of our study. However, it was found that the width of the piriform aperture of Brazilian population is higher in both genders in relation to Korean population evaluated by Lee et al. who obtained $24.34 \mathrm{~mm}$ and 22.82 $\mathrm{mm}$ of width of the piriform aperture for males and females, respectively. The results obtained by these authors confirm the results of Hwang et al., demonstrating that Korean population presents smaller dimensions of piriform aperture when compared with Brazilian population. This fact shows that the morphology and the dimensions of the piriform aperture can be an anatomic landmark used for ethnic differentiation in human identification (Suazo et al.).

The dimensions of the piriform aperture are higher in males than females Brazilian subjects and may contribute with the process of human identification. The type A of nasal bone was the most frequent in the Brazilian population contributing to ethnic differentiation in the human identification or in forensic context. The results of the piriform aperture and nasal bone morphology in the Brazilian population in this study may contribute to the process for identification of humans, especially in gender determination, and provide information for surgical procedures and nasal reconstruction in Otolaryngology.

ACKNOWLEDGMENTS. The authors thank for the financial support granted by Coordination for the Improvement of Higher Level or Education Personnel (Capes) and National Council for Scientific and Technological Development $(\mathrm{CNPq})$.

PRADO, F. B.; CALDAS, R. A.; ROSSI, A. C.; FREIRE, A. R.; GROPPO, F. C.; CARIA, P. H. F. \& JÚNIOR, E. D. Morfometría de la apertura piriforme y morfología de los huesos nasales en la población brasileña por la radiografía postero-anterior de Caldwell. Int. J. Morphol., 29(2):393-398, 2011.

RESUMEN: La apertura piriforme y el hueso nasal contribuyen a la formación de la nariz. Su morfología varía de acuerdo a los grupos étnicos y al sexo. Este estudio evaluó la morfología de la apertura piriforme y el hueso nasal y su relación con el sexo. Las aperturas piriformes y los huesos nasales de 97 personas fueron examinados radiográficamente mediante la técnica radiográfica de Caldwell, y los tipos de huesos nasales se clasificaron de acuerdo con Hwang et al. (2005). Se midió el ancho, la altura y el área de la apertura piriforme para demostrar las diferencias por sexo. El análisis estadístico se realizó a partir de la prueba t de Student y análisis de varianza (ANOVA). El tipo más frecuente de hueso nasal fue la A, y la D fue la menos común, en ambos sexos. En la prueba t de Student se obtuvo diferencias significativas entre los sexos, altura, ancho y área de la apertura piriforme, las que fueron mayores en hombres en comparación a las mujeres. Las dimensiones de la apertura piriforme fueron mayores en los hombres que en las mujeres, por lo que se puede utilizar como parámetro para la distinción de sexo en la población brasileña. En la población brasileña el tipo A de hueso nasal fue el más frecuente, lo que contribuye para la diferenciación étnica en la identificación humana.

PALABRAS CLAVE: Huesos nasales; Morfometría; Cavidad nasal; Cráneo.

\section{REFERENCES}

Abdelkader, M.; Leong, S.; White, P.S. Aesthetic proportions of the nasal aperture in 3 different racial groups of men. Arch. Facial Plast. Surg., 7:111-3, 2005.

Anderson, K. J.; Henneberg, M. \& Norris, R. M. Anatomy of the nasal profile. J. Anat., 213:210-6, 2008.

Camargo, J. R.; Daruge, E.; Prado, F. B.; Caria, P. H. F.; Alves, M. C.; Silva, R. F.; et al. The frontal sinus morphology in radiographs of Brazilian subjects: its forensic importance. Braz. J. Morphol. Sci., 24:1-5, 2007.
Cantín, L. M.; Suazo, G. I. C.; Zavando, M. D. A. \& Smith, R. L. Sexual dimorphism determination by piriform aperture morphometric analysis in Brazilian human skulls. Int. J. Morphol., 27:327-31, 2009.

Erdem, T.; Ozturan, O.; Erdem, G.; Akarcay, M. \& Miman, M. C. Nasal pyriform aperture stenosis in adults. Am. J. Rhinol., 18:57-62, 2004.

Hommerich, C. P. \& Riegel, A. Measuring of the piriform aperture in humans with 3D-SSD-CT-Reconstructions. 
PRADO, F. B.; CALDAS, R. A.; ROSSI, A. C.; FREIRE, A. R.; GROPPO, F. C.; CARIA, P. H. F. \& JÚNIOR, E. D. Piriform aperture morfometry and nasal bones morphology in Brazilian population by postero-anterior Caldwell radiographys. Int. J. Morphol., 29(2):393-398, 2011.

Ann. Anat., 184:455-9, 2002.

Hwang, T. S. \& Kang, H. S. Morphometry of nasal bases and nostrils in Koreans. Ann. Anat., 185:189-93, 2003.

Hwang, T. S.; Song, J.; Yoon, H.; Cho, B. P. \& Kang, H. S. Morphometry of the nasal bones and piriform apertures in Koreans. Ann. Anat., 187:411-4, 2005.

Lang, J. \& Baumeister, R. Über das postnatale Wachstum der Nasenhöhle. Gegenbaurs Morphol., 128:354-93, 1982.

Lee, S. E.; Yang, T. Y.; Han, G. S.; Kim, Y. H. \& Jang, T. Y. Analysis of the nasal bone and nasal pyramid by threedimensional computed tomography. Eur. Arch. Otorhinolaryngol., 265:421-4, 2008.

Prado, F. B.; de Mello Santos, L. S.; Caria, P. H. F.; Kawaguchi, J. T.; Preza, A. O. G.; Daruge J. E.; et al. Incidence of clavicular rhomboid fossa (impression for costoclavicular ligament) in the Brazilian population: forensic application. J. Forensic Odontostomatol., 27:126, 2009.

Rogers, T. L. Determining the sex of human remains through cranial morphology. J. Forensic. Sci., 50:493-500, 2005.

Sforza, C.; Dellavia, C.; Colombo, A.; Serrao, G. \& Ferrario, V. F. Nasal dimensions in normal subjects: conventional anthropometry versus computerized anthropometry. Am. J. Med. Genet. A, 130:228-33, 2004.

Shrestha, O.; Bhattacharya, S.; Jha, N.; Dhungel, S.; Jha, C. B.; Shrestha, S.; et al. Cranio facial anthropometric measurements among Rai and Limbu community of Sunsari District, Nepal. Nepal Med. Coll. J., 11:183-5, 2009.

Stephan, C. N. Facial approximation: an evaluation of mouth width determination. Am. J. Phys. Anthropol., 121:4857, 2003.

Suazo, G. I. C.; Zavando, M. D. A. \& Smith, R. L. Blind test of mandibular morphology with sex indicator in subadult mandibles. Int. J. Morphol., 26:845-8, 2008.

Swan, L. K. \& Stephan, C. N. Estimating eyeball protrusion from body height, interpupillary distance, and interorbital distance in adults. J. Forensic Sci., 50:774-6, 2005.
Taylor, K. T. Forensic Art and Illustration. Boca Raton, CRC Press, 2001.

Vitte, E.; Guerin-Surville, H.; Baulac, M. \& Cabrol, C. Morphometric study of the piriform aperture. Bull Assoc. Anat., 67:347-54, 1982.

Wilkinson, C. Forensic Facial Reconstruction. Cambridge, Cambridge University Press, 2004.

Williams, B. A. \& Rogers, T. Evaluating the accuracy and precision of cranial morphological traits for sex determination. J. Forensic Sci., 51:729-35, 2006.

Wolpoff, M. H. Climatic influence on the skeletal nasal aperture. Am. J. Phys. Anthropol., 29:405-23, 1968.

Correspondence to:

Ms. Ana Cláudia Rossi

Postgraduate student, Anatomy area

Department of Morphology

State University of Campinas - UNICAMP

Av. Limeira, 901 Areião, CP52

CEP: 13414-903

Piracicaba, SP

BRAZIL

Email: anaclaudiarossi@fop.unicamp.br

Received: 16-11-2010

Accepted: 24-02-2011 